Gut, 1973, 14, 354-359

\title{
Skeletal muscle blood flow and neurovascular reactivity in liver disease ${ }^{1}$
}

\author{
MICHAEL LUNZER, S. P. NEWMAN, AND SHEILA SHERLOCK \\ From the Departments of Medicine and Physics, Royal Free Hospital, London
}

SUMMARY There was no significant difference in forearm muscle blood flow, measured by the clearance of ${ }^{133}$ Xenon when 38 patients with liver disease were compared with 38 normal subjects. Patients with a clinically hyperdynamic circulation, finger clubbing, and previous portocaval anastomoses were included in the study.

The changes in forearm skeletal muscle blood flow and pulse rate caused by a head-up tilt of 70 degrees were measured in 15 patients with chronic liver disease and 15 age-matched controls. Head-up tilting resulted in significantly less peripheral vasoconstriction and tachycardia in the group with liver disease than in the control group.

These results suggest an impairment of baroreceptor-mediated sympathetic reactivity in liver disease. Such a defect might explain the relative rarity of hypertension in patients with cirrhosis.

A hyperdynamic circulation is often found in patients with liver disease (Kontos, Shapiro, Page Mauck, and Patterson, 1964; Murray, Dawson, and Sherlock, 1958) and increased blood flow to the hand has been demonstrated in cirrhosis (Abramson and Lichtman, 1937; Martini and Hagemann, 1956). As it is generally accepted that blood flow to the hand is almost entirely cutaneous (Kontos et al, 1964), skin blood flow would appear to be increased in liver disease.

The major components of forearm blood flow in normal subjects at rest are those to skin and skeletal muscle (Cooper, Edholm, and Mottram, 1955). Kontos et al (1964) have presented indirect evidence that in some patients with cirrhosis there are increases in both muscle and skin blood flow whereas in others only one of these two components is increased. However, there has been no direct evaluation of skeletal muscle blood flow in liver disease.

The factors responsible for the circulatory changes of liver disease are unknown, many unsuccessful attempts having been made to identify a humoral vasodilator substance. We have investigated neurovascular responsiveness in patients with chronic liver disease in order to determine a possible alter-

\footnotetext{
${ }^{1}$ Presented at the Vth Meeting of the International Association for the Study of the Liver at Versaillles in July 1972.

Received for publication 8 February 1973
}

native explanation for these circulatory changes. Head-up tilting from the horizontal position is a powerful stimulus to the baroreceptors in the low pressure vascular compartments in the chest. Firing of these baroreceptors results in reflex vasoconstriction of blood vessels in the forearm and a concomitant tachycardia. These reflexes are transmitted via the sympathetic nervous system.

\section{Methods}

Skeletal muscle blood flow was measured using the technique of Lassen (Lassen, Lindbjerg, and Munck, 1964). All subjects were supine and had neither eaten nor smoked for at least two hours. Studies were performed at room temperature $\left(23-26^{\circ} \mathrm{C}\right)$.

${ }^{133}$ Xenon gas, $150-250 \mu \mathrm{Ci}$, dissolved in not more than $0.15 \mathrm{ml}$ of saline was injected directly into the brachioradialis muscle. The injection was given over a 15-second period and the needle left in situ for a further 15 seconds. At least 15 minutes was allowed to elapse before recording was commenced.

The clearance of xenon was monitored by a scintillation detector connected to a rate meter with a three-second time constant and thence to a potentiometric chart recorder.

The clearance curve was replotted on log-linear graph paper as a straight line and the best-fit slope was found using linear regression analysis.

Skeletal muscle blood flow in $\mathrm{ml} 100 \mathrm{~g}^{-1} \mathrm{~min}^{-1}$ was calculated from the formula $100 \lambda \mathrm{K}$, where $\lambda$ is the 
partition coefficient for xenon between muscle and blood, and $\mathrm{K}$, the slope of the best-fit line, is the fraction of activity cleared from the forearm per unit time.

In the second part of the study skeletal muscle blood flow was measured with the subject horizontal and repeated with the subject tilted head-up at an angle of 70 degrees to the horizontal. Count rates at 30 -second intervals were recorded on a digital rate meter and were used to calculate skeletal muscle blood flow before and after tilting using linear regression analysis. A few recordings with regression coefficients of less than 0.975 were discarded. Pulse rates were measured immediately before and after tilting.

\section{Results}

Resting skeletal muscle blood flow was estimated in 38 patients with liver disease and 38 controls.

The control group was composed of 11 normal volunteers, 12 patients admitted for minor surgical procedures, and 15 patients with various medical conditions unrelated to the liver. The mean age of this group was 39.7 (SD 12.6) years.

The composition of the group with liver disease was as follows:

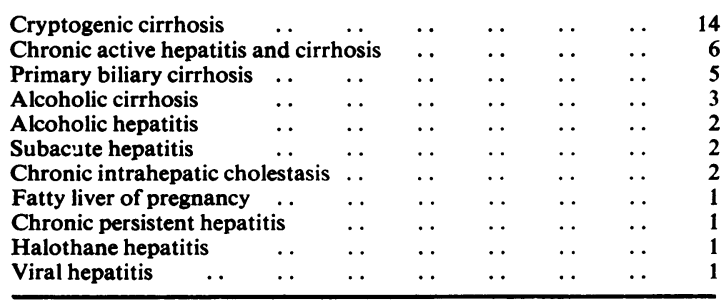

The mean age of this group was $41 \cdot 3$ years (SD 13.8).

The mean resting skeletal muscle blood flow in the control group was $1.48 \mathrm{ml} 100 \mathrm{~g}_{\text {muscle }}{ }^{-1}$ minute $^{-1}$ (SD 0.56) while the group with liver disease had a mean flow of $1.40 \mathrm{ml} 100 \mathrm{~g}$ muscle $^{-1}$ minute $^{-1}$ (SD 0.51). There was no significant difference in blood flow between the two groups ( $P$ between 0.4 and 0.5 ) (fig 1).

The group with liver disease included patients with clinically hyperdynamic circulations, finger clubbing, and previous portocaval anastomoses (fig 2). Muscle blood flow was not increased in these groups and, if anything, was decreased in the patients with finger clubbing.

The changes in skeletal muscle blood flow and pulse rate due to head-up tilting were measured in 15 patients with chronic liver disease and 15 age-

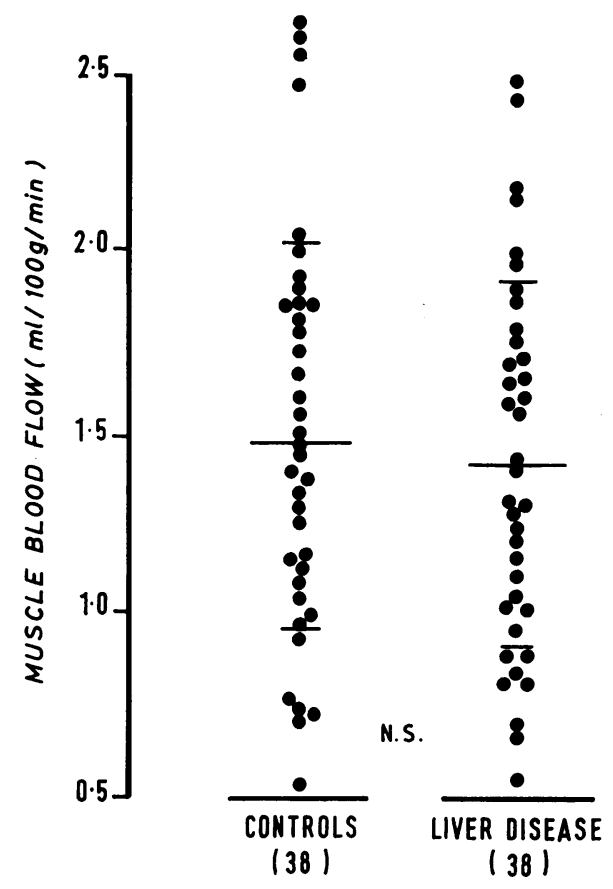

Fig 1 Forearm skeletal muscle blood flow in liver disease and controls.

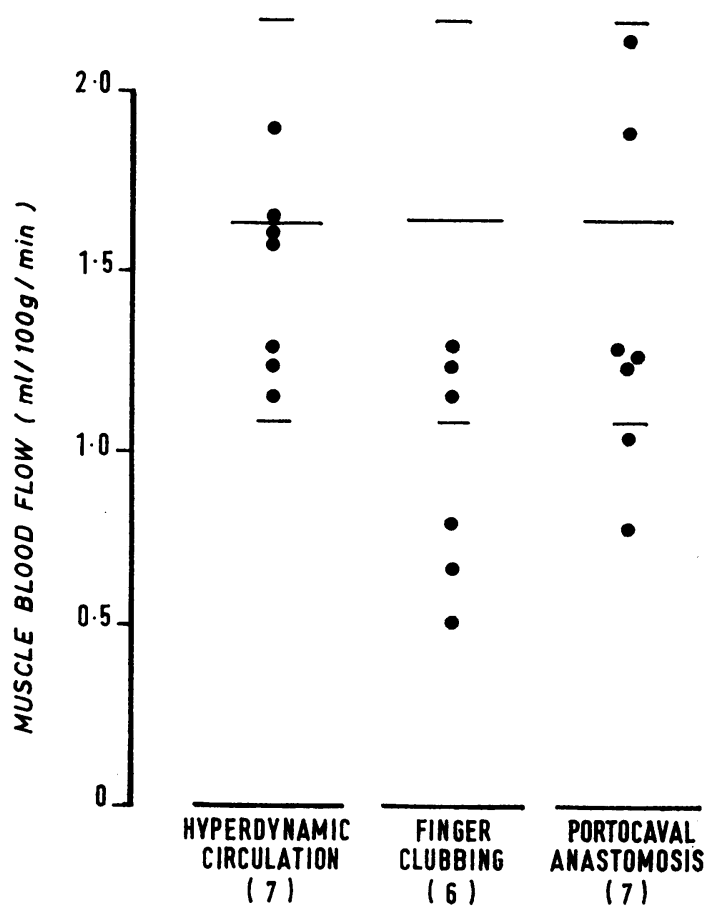

Fig 2 Skeletal muscle blood flow in liver disease. 
matched controls (see table). The changes in flow are shown diagrammatically in fig 3 and expressed as percentage decreases in figure 4 . There was no history of excessive alcohol consumption in the patients with liver disease, nor was there any clinical evidence of diabetes or peripheral neuropathy. No subjects were receiving drugs known to affect peripheral blood flow or impair vasoconstriction.

There was a highly significant difference between the two groups, the patients with liver disease showing less vasoconstriction than the control subjects $(P<0.001)$.

Radial pulse rates before and after vertical tilting showed a highly significant difference between the two groups, patients with liver disease showing less tachycardia in response to tilting than the control group (P $<0.001$ ) (fig 5 and fig 6 ).

\section{Discussion}

Clinical stigmata of liver disease thought to be related to peripheral vasodilatation include warm extremities, bounding pulses, haemic ejection murmurs, spider angiomata, and clubbing of the fingers.

The increased cardiac output and decreased peripheral resistance of other 'high-output states', such as thyrotoxicosis and arteriovenous fistulae, have been well described in patients with cirrhosis (Murray et al, 1958; Kowalski and Abelmann, 1953). However, 'high-output' cardiac failure appears to be distinctly uncommon in liver disease (Sherlock, 1971).

It was the expectation of previous authors that in patients with liver disease there would be increases in both peripheral muscle and skin blood flow

\begin{tabular}{|c|c|c|c|c|c|c|c|c|c|}
\hline \multirow{2}{*}{$\begin{array}{l}\text { Patient } \\
\text { No. }\end{array}$} & \multirow[t]{2}{*}{ Age } & \multirow[t]{2}{*}{$\operatorname{Sex}$} & \multirow[t]{2}{*}{ Diagnosis } & \multicolumn{3}{|c|}{ Muscle Blood Flow } & \multicolumn{3}{|l|}{ Pulse Rates } \\
\hline & & & & Horizontal & Vertical & $\begin{array}{l}\text { Percentage } \\
\text { Decrease }\end{array}$ & Horizontal & Vertical & $\begin{array}{l}\text { Percentage } \\
\text { Increase }\end{array}$ \\
\hline \multicolumn{10}{|l|}{ Controls } \\
\hline 1 & 28 & $\mathbf{M}$ & Normal & 0.93 & 0.33 & $64 \cdot 5$ & 77 & 100 & 30 \\
\hline 2 & 28 & $\mathbf{M}$ & Normal & 1.59 & 0.57 & $64 \cdot 2$ & 80 & 92 & 15 \\
\hline 3 & 53 & $\mathbf{M}$ & Irritable colon & $1 \cdot 38$ & 1.00 & $27 \cdot 5$ & 72 & 86 & 19 \\
\hline 4 & 28 & $\mathbf{M}$ & Mitral stenosis & 1.73 & 0.90 & $48 \cdot 0$ & 78 & 104 & 33 \\
\hline 5 & 28 & $\mathbf{M}$ & Normal & 1.90 & 0.65 & $65 \cdot 8$ & 72 & 92 & 28 \\
\hline 6 & 22 & $\mathbf{M}$ & Normal & $1 \cdot 15$ & 0.45 & 60.9 & 74 & 92 & 20 \\
\hline 7 & 40 & $\mathbf{M}$ & Scurvy & $1 \cdot 34$ & 0.98 & $26 \cdot 9$ & 78 & 104 & 33 \\
\hline 8 & 40 & $\mathbf{M}$ & Anxiety state & 0.97 & 0.39 & 59.8 & 94 & 102 & 9 \\
\hline 9 & 39 & $\mathbf{M}$ & Pilonidal sinus & $2 \cdot 64$ & 1.07 & $59 \cdot 5$ & 92 & 116 & 26 \\
\hline 10 & 38 & $\mathbf{M}$ & After laparotomy & $1 \cdot 93$ & 0.86 & $55 \cdot 4$ & 74 & 108 & 46 \\
\hline 11 & 40 & $\mathbf{M}$ & Antritis & $2 \cdot 02$ & 1.01 & $50 \cdot 0$ & 74 & 96 & 30 \\
\hline 12 & 48 & $\mathbf{F}$ & Diarrhoea & $2 \cdot 56$ & $1 \cdot 19$ & $53 \cdot 5$ & 84 & 96 & 14 \\
\hline 13 & 62 & $\mathbf{M}$ & Renal calculus & $1 \cdot 51$ & 0.49 & $67 \cdot 5$ & 82 & 90 & 10 \\
\hline 14 & 43 & $\mathbf{F}$ & Obesity & 1.08 & 0.57 & $47 \cdot 2$ & 58 & 67 & 16 \\
\hline 15 & 38 & $\mathbf{M}$ & Mastoiditis & $1 \cdot 78$ & 0.31 & $82 \cdot 6$ & 75 & 90 & 20 \\
\hline \multicolumn{3}{|c|}{$\begin{array}{l}\text { Mean age } 38.3 \text { years } \\
\text { (SD 10.7) }\end{array}$} & \multicolumn{4}{|c|}{$\begin{array}{l}\text { Mean } 55 \cdot 6 \% \\
(\mathrm{SD} 14 \cdot 6)\end{array}$} & \multicolumn{2}{|r|}{$\begin{array}{l}\text { Mean } \\
\text { (SD }\end{array}$} & $\begin{array}{l}23 \cdot 3 \% \\
10 \cdot 2)\end{array}$ \\
\hline \multicolumn{10}{|c|}{ Liver Disease } \\
\hline 1 & 40 & $\mathbf{M}$ & Primary biliary cirrhosis & 0.87 & 0.65 & $25 \cdot 3$ & 84 & 100 & 19 \\
\hline 2 & 23 & $\mathbf{M}$ & Cryptogenic cirrhosis & $1 \cdot 60$ & $1 \cdot 25$ & $21 \cdot 9$ & 70 & 76 & 9 \\
\hline 3 & 48 & $\mathbf{M}$ & Primary biliary cirrhosis & 1.99 & $1 \cdot 30$ & $34 \cdot 7$ & 77 & 84 & 9 \\
\hline 4 & 47 & $\mathbf{M}$ & Cryptogenic cirrhosis & $1 \cdot 23$ & 0.82 & $33 \cdot 3$ & 72 & 82 & 14 \\
\hline 5 & 61 & $\mathbf{M}$ & Cryptogenic cirrhosis & $2 \cdot 43$ & $1 \cdot 42$ & $41 \cdot 6$ & 78 & 78 & 0 \\
\hline 6 & 43 & $\mathbf{M}$ & Primary biliary cirrhosis & $1 \cdot 19$ & 0.71 & $40 \cdot 3$ & 92 & 108 & 17 \\
\hline 7 & 37 & $\mathbf{M}$ & Primary biliary cirrhosis & $1 \cdot 58$ & $1 \cdot 27$ & $19 \cdot 6$ & 92 & 94 & 2 \\
\hline 8 & \multirow{2}{*}{$\begin{array}{l}61 \\
18\end{array}$} & $\mathbf{M}$ & Cryptogenic cirrhosis & 0.52 & 0.44 & $15 \cdot 4$ & 76 & 76 & 0 \\
\hline 9 & & $\mathbf{F}$ & $\begin{array}{l}\text { Chronic active hepatitis } \\
\text { and cirrhosis }\end{array}$ & $1 \cdot 41$ & $1 \cdot 16$ & $17 \cdot 7$ & 98 & 106 & 8 \\
\hline \multirow[t]{2}{*}{10} & \multirow[t]{2}{*}{38} & \multirow[t]{2}{*}{$\mathbf{F}$} & \multirow{2}{*}{$\begin{array}{l}\text { Chronic active hepatitis } \\
\text { and cirrhosis }\end{array}$} & & & & & & \\
\hline & & & & 1.86 & $1 \cdot 33$ & $28 \cdot 5$ & 88 & 96 & 9 \\
\hline \multirow{2}{*}{$\begin{array}{l}11 \\
12\end{array}$} & \multirow{2}{*}{$\begin{array}{l}22 \\
44\end{array}$} & \multirow{2}{*}{$\begin{array}{l}\mathbf{F} \\
\mathbf{M}\end{array}$} & \multirow{2}{*}{$\begin{array}{l}\text { Cryptogenic cirrhosis } \\
\text { Chronic active hepatitis } \\
\text { and cirrhosis }\end{array}$} & 1.97 & 0.82 & $58 \cdot 4$ & 80 & 82 & 3 \\
\hline & & & & & & & & & \\
\hline \multirow[t]{2}{*}{13} & \multirow[t]{2}{*}{20} & $\mathbf{M}$ & $\begin{array}{l}\text { and cirrhosis } \\
\text { Chronic active hepatitis }\end{array}$ & $2 \cdot 48$ & 1.86 & 25.0 & 76 & 88 & 16 \\
\hline & & & and cirrhosis & $1 \cdot 74$ & $1 \cdot 31$ & $24 \cdot 7$ & 76 & 86 & 13 \\
\hline 14 & 25 & $\mathbf{F}$ & Primary biliary cirrhosis & $2 \cdot 18$ & $1 \cdot 76$ & $19 \cdot 3$ & 70 & 78 & 11 \\
\hline 15 & 40 & $\mathbf{M}$ & Cryptogenic cirrhosis & $2 \cdot 15$ & $1 \cdot 12$ & 47.9 & 70 & 76 & 9 \\
\hline $\begin{array}{r}\text { Mean age } \\
\text { (SD }\end{array}$ & $\begin{array}{l}37 \cdot 7 y \\
13 \cdot 8)\end{array}$ & years & & & & $\begin{array}{l}30 \cdot 2 \% \\
12 \cdot 3)\end{array}$ & & $\begin{array}{l}\text { Mean } \\
\text { (SD }\end{array}$ & $\begin{array}{l}9 \cdot 3 \% \\
6 \cdot 0)\end{array}$ \\
\hline
\end{tabular}

Table Results in controls and in patients with liver disease 

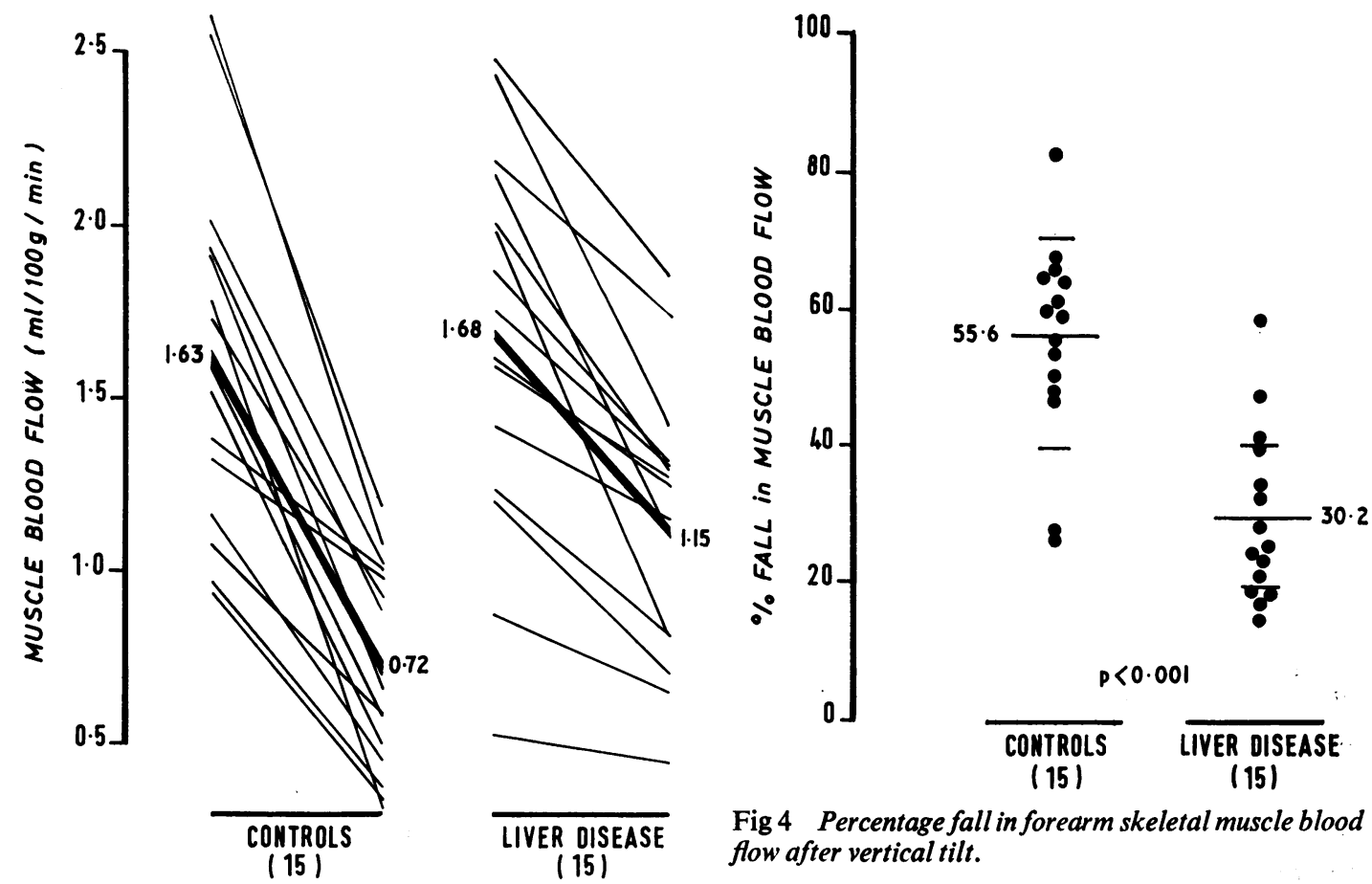

Fig 3 Change in forearm muscle blood flow after vertical tilt.
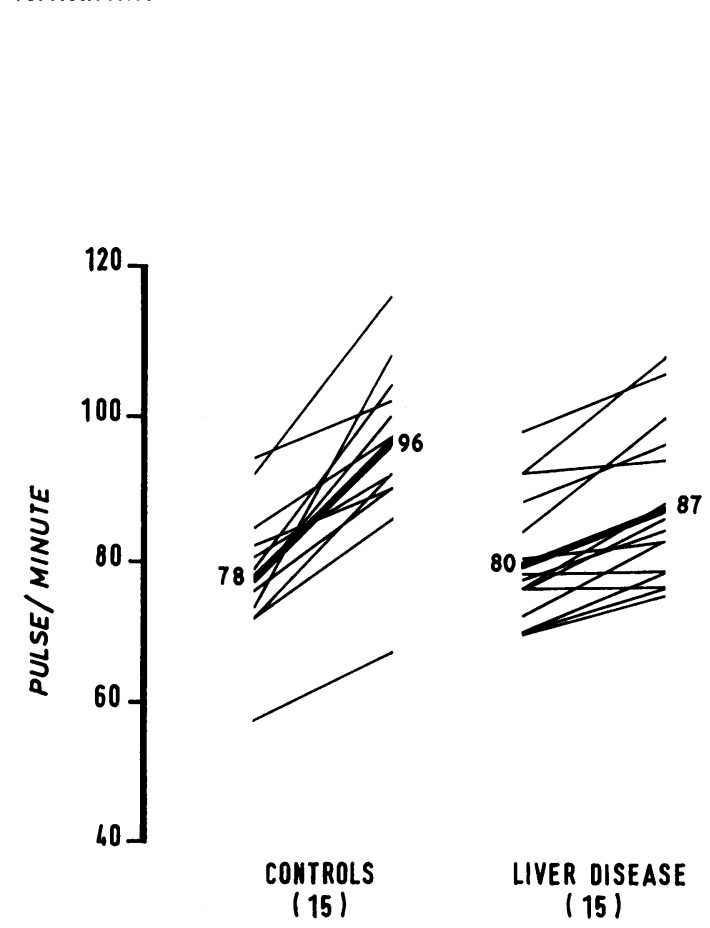

Fig 4 Percentage fall in forearm skeletal muscle blood flow after vertical tilt.

Fig 5 Pulse change after vertical tilt.

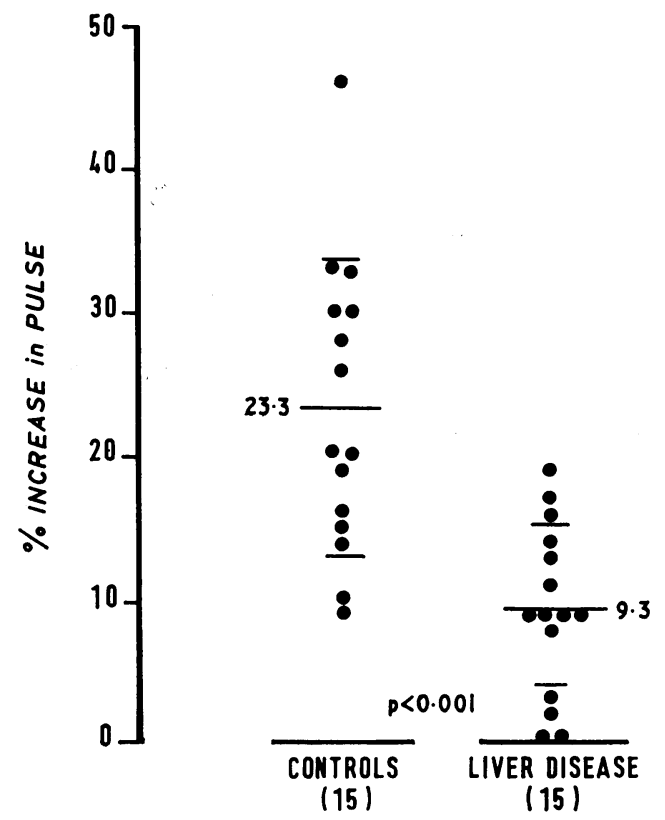

Fig 6 Pulse increase after vertical tilt. 
(Kontos et al, 1964; Abramson, Fierst, and Flachs, 1943). However, we have shown forearm skeletal muscle blood flow to be normal in patients with various forms of liver disease, suggesting that the peripheral vasodilatation is entirely cutaneous in origin.

The patients with a clinically hyperdynamic circulation and finger clubbing, signs that have usually been associated with a high total peripheral blood flow (Kontos et al, 1964; Martini and Hagemann, 1956), did not show an increase in skeletal muscle blood flow (fig 2). Ginsburg (1958) has shown that in some patients with clubbing due to hypertrophic pulmonary osteoarthropathy flow in the forearm and calf is increased, whilst that of the resting hand and foot is normal. This suggests that skeletal muscle blood flow is increased in such patients in contrast to our findings in patients with cirrhosis. Several mechanisms responsible for clubbing have been suggested and it is possible that the factors involved are different in the two diseases. The large internal diversion of venous blood created by portocaval anastomoses did not appear to affect skeletal muscle blood flow.

When the normal subject is tilted from the supine to the erect posture there is a decrease in forearm blood flow and an increase in pulse rate that do not occur in the sympathectomized forearm (Brigden, Howarth, and Sharpey-Schafer, 1950). These reflexes are thought to be transmitted by thoracic baroreceptors via the sympathetic nervous system.

In 1956 Sharpey-Schafer demonstrated the absence of baroreceptor reflexes in patients suffering from tabes dorsalis (Sharpey-Schafer, 1956). Subsequently impaired vasoconstrictor responses following vertical tilting or lower body negative pressure have been described in a variety of disorders including orthostatic hypotension (Bannister, Ardill, and Fentem, 1967; Burns, Downey, Frewin, and Whelan, 1971), peripheral neuritis (Barraclough and Sharpey-Schafer, 1963), diabetes (Odel, Roth, and Keating, 1955), Parkinson's syndrome (Appenzeller and Goss, 1971), and chronic hypoxaemia (Heistad, Abboud, Mark, and Schmid, 1972).

It has been emphasized that defective circulatory reflexes are most likely to be associated with hypotension if there is acute interruption of the reflex and that with a chronic baroreceptor block hypotension may only develop with a reduction in blood volume (Barraclough and Sharpey-Schafer, 1963). Plasma volume is frequently increased in patients with cirrhosis (Eisenberg, 1956; McCloy, Baldus, Tauxe, and Summerskill, 1967) and this increase may exert a protective influence against the development of symptomatic hypotension. Severe hepatic failure may, however, be associated with hypotension and in these cases the plasma volume is often reduced.

The finding of hypertension among patients with chronic liver disease is very unusual (Loyke, 1955; Loyke, 1962a; Spatt and Rosenblatt, 1949) and previous hypertension has been found to revert to normal blood pressure with the development of cirrhosis (Loyke, 1962b).

Our results suggest that patients with chronic liver disease have an impairment of peripheral vasoconstriction. Such a defect may be responsible for the peripheral vasodilatation and the relative rarity of hypertension in patients with liver disease. It may also contribute to the development of hypotension in severe hepatic failure.

Recent work by Fischer and his colleagues (Fischer and Baldessarini, 1971; Fischer and James, 1972) has suggested that some of the neurological and cardiovascular complications of hepatic failure might be explained by the accumulation of false adrenergic neurochemical transmitters. It is postulated that 'false neurotransmitters' replace the physiological transmitters, noradrenaline and dopamine, in the nerve endings and that stimulation of these nerve endings results in release of less active transmitters with consequent diminution in the response of the effector organ. Such an hypothesis could explain a defect in sympathetic vasoconstriction in liver disease as noradrenergic transmission is required for this reflex.

We wish to thank Mr H. S. Williams, Physics Department, Royal Free Hospital, for his most helpful advice during this study. M.L. was initially supported by a grant from the Ingram Trust and is at present the Watson Smith Fellow of the Royal College of Physicians.

\section{References}

Abramson, D. I., Fierst, S. M., and Flachs, K. (1943). Rate of peripheral blood flow in presence of edema. Amer. Heart J., 25, 328-334.

Abramson, D. I., and Lichtman, S. S. (1937). Influence of ergotamine tartrate upon peripheral blood-flow in subjects with liver disease. Proc. Soc. exp. Biol. (N.Y.), 37, 262-267.

Appenzeller, O., and Goss, J. E. (1971). Autonomic deficits in Parkinson's syndrome. Arch. Neurol., 24, 50-57.

Bannister, R., Ardill, L., and Fentem, P. (1967). Defective autonomic control of blood vessels in idiopathic orthostatic hypotension. Brain, 90, 725-746.

Barraclough, M. A., and Sharpey-Schafer, E. P. (1963). Hypotension from absent circulatory reflexes. Lancet, 1, 1121-1126.

Bridgen, W., Howarth, S., and Sharpey-Schafer, E. P. (1950). Postural changes in the peripheral blood-flow of normal subjects with observations on vasovagal fainting reactions as result of tilting, the lordotic posture, pregnancy and spinal anaesthesia. Clin. Sci., 9, 79-91.

Burns, R. J., Downey, J. A., Frewin, D. B., and Whelan, R. F. (1971). Autonomic dysfunction with orthostatic hypotension. Aust. N.Z. J. Med., 1, 15-21.

Cooper, K. E., Edholm, O. G., and Mottram, R. F. (1955). The blood flow in skin and muscle of the human forearm. J. Physiol. (Lond.), 128, 258-267.

Eisenberg, S. (1956). Blood volume in patients with Laennec's cirrhosis 
of the liver as determined by radioactive chromium tagged red cells. Amer. J. Med., 20, 189-195.

Fischer, J. E., and Baldessarini, R. J. (1971). False neurotransmitters and hepatic failure. Lancet, 2, 75-79.

Fischer, J. E., and James, J. H. (1972). Treatment of hepatic coma and hepatorenal syndrome. Amer. J. Surg., 123, 222-230.

Ginsburg, J. (1958). Observations on the peripheral circulation in hypertrophic pulmonary osteoarthropathy. Quart. J. Med., 27, 335-352.

Heistad, D. D., Abboud, F. M., Mark, A. L., and Schmid, P. G. (1972). Impaired reflex vasoconstriction in chronically hypoxemic patients. J. clin. Invest., 51, 331-337.

Kontos H. A., Shapiro, W., Page Mauck, H., and Patterson, J. L., Jr. (1964). General and regional circulatory alterations in cirrhosis of the liver. Amer. J. Med., 37, 526-535.

Kowalski, H. J., and Abelmann, W. H. (1953). The cardiac output at rest in Laennec's cirrhosis. J. clin. Invest., 32, 1025-1033.

Lassen, N. A., Lindbjerg, I. F., and Munck, O. (1964). Measurement of blood flow through skeletal muscle by intramuscular injection of Xenon-133. Lancet, 1, 686-689.

Loyke, H. F. (1955). The relationship of cirrhosis of the liver to hypertension: a study of 504 cases of cirrhosis of the liver. Amer. J. med. Sci., 230, 627-632.
Loyke, H. F. (1962a). Hypertension and liver disease: a clinical and experimental review. Amer. J. Gastroent., 38, 56-59.

Loyke, H. F. (1962b). Reduction of hypertension after liver disease. Arch. intern. Med., 110, 45-49.

McCloy, R. M., Baldus, W. P., Tauxe, W. N., and Summerskill, W. H. J. (1967). Plasma volume and renal circulatory function in cirrhosis. Ann. intern. Med., 66, 307-311.

Martini, G. A., and Hagemann, J. E. (1956). Uber Fingernagelveranderungen bei Lebercirrhose als Folge veränderter peripherer Durchblutung. Klin. Wschr., 34, 25-31.

Murray, J. F., Dawson, A. M., and Sherlock, S. (1958). Circulatory changes in chronic liver disease. Amer. J. Med., 24, 358-367.

Odel, H. M., Roth, G. M., and Keating, F. R., Jr. (1955). Autonomic neuropathy simulating the effects of sympathectomy as a complication of diabetes mellitus. Diabetes, 4, 92-98.

Sharpey-Schafer, E. P. (1956). Circulatory reflexes in chronic disease of the afferent nervous system. J. Physiol. (Lond.), 134, 1-10.

Sherlock, S. (1971). Diseases of the Liver and Biliary System, 4th ed., p. 82. Blackwell, Oxford.

Spatt, S. D., and Rosenblatt, P. (1949). The incidence of hypertension in portal cirrhosis. Ann. intern. Med., 31, 479-483. 